\title{
Delayed Bleeding After Endoscopic Resection of Colorectal Polyps: Identifying High-Risk Patients
}

\author{
Oliver Bendall \\ Joel James' \\ Katarzyna M Pawlak (D) ${ }^{2}$ \\ Sauid Ishaq 3,4 \\ J Andy Tau ${ }^{5}$ \\ Noriko Suzuki ${ }^{6}$ \\ Steven Bollipo iD 7,8 \\ Keith Siau (D) \\ 'Department of Gastroenterology, Royal \\ Cornwall Hospitals NHS Trust, Truro, \\ UK; ${ }^{2}$ Endoscopy Unit, Department of \\ Gastroenterology, Ministry of Interior \\ and Administration, Szczecin, Poland; \\ ${ }^{3}$ Department of Gastroenterology, \\ Dudley Group Hospitals NHS Foundation \\ Trust, Dudley, UK; ${ }^{4}$ Medicine, \\ Birmingham City Hospital, Birmingham, \\ UK; ${ }^{5}$ Austin Gastroenterology, Austin, \\ TX, USA; ' Wolfson Unit for Endoscopy, \\ St. Mark's Hospital, London, UK; ${ }^{7}$ School \\ of Medicine \& Public Health, The \\ University of Newcastle, Callaghan, New \\ South Wales, Australia; ${ }^{8}$ Department of \\ Gastroenterology, John Hunter Hospital, \\ New Lambton Heights, New South \\ Wales, Australia
}

\begin{abstract}
Delayed post-polypectomy bleeding (DPPB) is a potentially severe complication of therapeutic colonoscopy which can result in hospital readmission and re-intervention. Over the last decade, rates of DPPB reported in the literature have fallen from over $2 \%$ to $0.3-1.2 \%$, largely due to improvements in resection technique, a shift towards cold snare polypectomy, better training, adherence to guidelines on periprocedural antithrombotic management, and the use of antithrombotics with more favourable bleeding profiles. However, as the complexity of polypectomy undertaken worldwide increases, so does the importance of identifying patients at increased risk of DPPB. Risk factors can be categorised according to patient, polyp and personnel related factors, and their integration together to provide an individualised risk score is an evolving field. Strategies to reduce DPPB include safe practices relevant to all patients undergoing colonoscopy, as well as specific considerations for patients identified to be high risk. This narrative review sets out an evidence-based summary of factors that contribute to the risk of DPPB before discussing pragmatic interventions to mitigate their risk and improve patient safety.
\end{abstract}

Keywords: colonoscopy, polypectomy, haemorrhage, adverse event, complications

\section{Introduction}

High-quality colonoscopy and polypectomy reduces mortality from colorectal cancer. ${ }^{1}$ In the last decade, the global focus on colorectal cancer screening and high-quality colonoscopy has led to an increasing trend in colonoscopies, ${ }^{2}$ improved lesion detection, ${ }^{2,3}$ with a resultant disproportionate increase in polypectomy rates. Post-polypectomy bleeding is an infrequent complication and may be immediate or delayed. The overall incidence of delayed post polypectomy bleeding (DPPB) for colorectal polyps varies between $0.3 \%$ and $1.2 \%,{ }^{4-6}$ and increases to $6.2 \%$ for larger $(>20 \mathrm{~mm})$ lesions. $^{7}$ Despite the low incidence, the burden of DPPB is potentially high due to the frequency of polypectomy, considering lesion detection rates of $25-45 \%{ }^{8,9}$ Moreover, with advances and widespread adoption of endoscopic resection techniques including endoscopic submucosal dissection, endoscopic resection has increasingly replaced surgery as the preferred therapeutic approach, even for complex and malignant polyps. Taken together, DPPB represents an important cause of morbidity and health-careassociated cost ${ }^{10}$ which is a potentially predictable and avoidable complication of colonoscopy.

This narrative review aims to provide an evidence-based summary for identifying patients at high risk of DPPB and to discuss pragmatic interventions to mitigate
Correspondence: Keith Siau

Department of Gastroenterology, Royal Cornwall Hospitals NHS Trust, Truro,

TRI 3LJ, UK

Email keithsiau@nhs.net 
risk and improve patient safety. This will cover endoscopic techniques for resecting conventional colorectal polyps (adenomas and serrated lesions). Full-thickness resection (including surgical hybrid resection techniques) and postpolypectomy perforations are beyond the scope of this paper.

\section{Definition of Post-Polypectomy Bleeding}

Post polypectomy bleeding can be broadly categorised into immediate (intraprocedural) and delayed (postprocedural) bleeding. The European Society of Gastrointestinal Endoscopy (ESGE) defines DPPB as bleeding that occurs after the end of the procedure and up to 30 days postpolypectomy which results in emergency attendance, hospitalisation, or need for re-intervention. ${ }^{11}$ The British Society of Gastroenterology (BSG) stratifies severity into minor, intermediate, major or fatal according to the need for hospitalisation and degree of intervention required. ${ }^{12}$

\section{Literature Search}

A literature search was performed on MEDLINE and PubMed to identify relevant articles between 2005 and 2021. Articles were identified using a combination of the following broad search formula: "polyp" OR "polypectomy” OR "post-polypectomy” AND "bleed" OR "haemorrhage". Full-text articles in English were reviewed to only include colorectal polyps. Relevant international guidelines were also reviewed.

\section{Pathogenesis of DPPB}

Various mechanisms have been proposed in the pathogenesis of DPPB (Figure 1). The objective of polypectomy is to ensure complete lesion resection with clear depth and margins (R0), and should be ideally performed en bloc to facilitate histological staging. Polypectomy inherently results in a mucosal defect with a varying degree of submucosal tissue and vessel injury, ${ }^{13}$ the effects of which are accentuated with heat. Over time, mucosal reepithelialization of the defect occurs. However, ulceration due to premature sloughing of the temporary wound eschar may expose an underlying blood vessel before reepithelialization is complete. ${ }^{14,15}$ This may be spontaneous, or traumatic related to passage of stool across the polypectomy site. Alternatively, extension of thermal injury and zone of necrosis may extend to previously noninjured tissue including blood vessels. ${ }^{14}$ Diathermy, and adrenaline, results in temporary vasoconstriction of surrounding blood vessels and contraction of surrounding tissues, but may lead to bleeding once these effects wear off post-procedure. Intravascular factors will also contribute to risk, with bleeding more likely in a higher flow state such as a large vessel in a pedunculated polyp stalk, high flow rates within a vessel (eg, from systemic hypertension), ${ }^{16}$ or in the presence of an inherited or acquired coagulopathy.

\section{Risk Factors for DPPB}

Risk factors for DPPB can be systematically categorised using the 3P's: a) Patient-related factors (including antithrombotics), b) Polyp-related factors, and c) Personnel-related factors. The main risk factors and their effect size, as described in the original literature, are displayed in Table 1.

\section{Patient-Related Factors}

Many patient-related factors affect the risk of DPPB, the majority of which are non-modifiable. These must be clearly considered on an individual basis during the consent process. Whilst co-morbidities may not predict the risk of DPPB, they bear consideration when assessing the impact and physiological reserve to withstand haemorrhage.

\section{Demographics}

No demographic factors such as age, sex or race, have been consistently shown to affect the incidence of DPPB. ${ }^{17,18}$ In a recent systematic review and metaanalysis of 12 studies, increasing age was not associated with increased risk of DPPB (mean difference 1.68; $-1.83-5.20),{ }^{17}$ although data appear conflicting within the literature. ${ }^{19,20}$ One study reported a positive association between body mass index $>25$ and DPPB. ${ }^{21}$ Patients with blood group $\mathrm{O}$ are associated with increased bleeding tendency due to lower von Willebrand factor and factor VIII levels; ${ }^{22}$ a multi-centre retrospective study identified blood group $\mathrm{O}$ as an independent risk factor for DPPB (adjusted odds ratio [OR] 1.6). ${ }^{23}$

\section{Comorbidities}

In the aforementioned meta-analysis, only hypertension (OR $1.53 ; 95 \%$ CI 1.12-2.11) and a history of cardiovascular disease (OR 1.55; 95\% CI 1.08-2.21) were associated with DPPB, although only a few of the included studies accounted for the confounding effect of antithrombotics. Diabetes, cerebrovascular disease, smoking and alcohol were not associated 


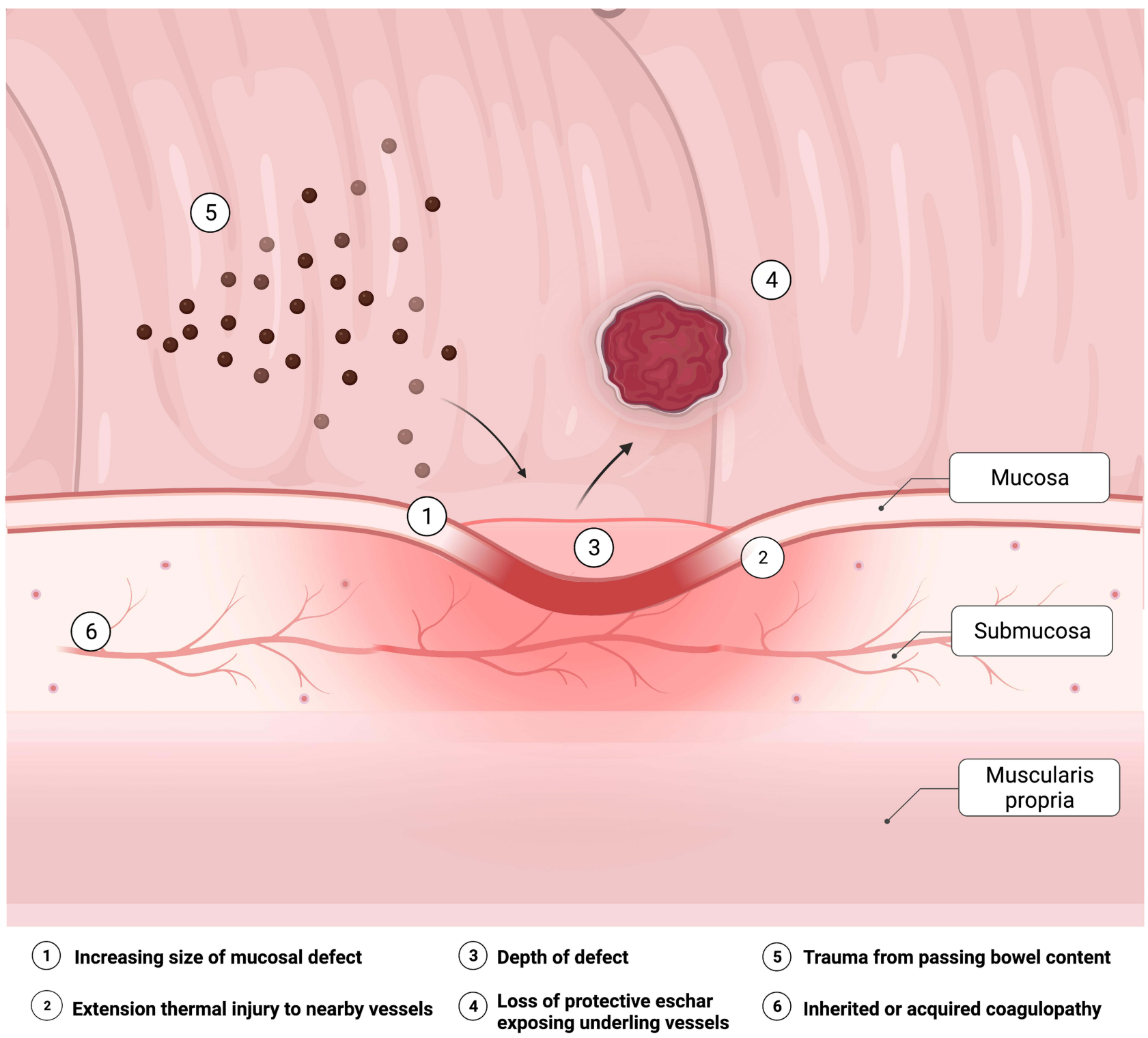

Figure I Factors contributing to the pathophysiology of delayed post-polypectomy bleeding.

with DPPB. ${ }^{17}$ The effect of chronic liver disease has been examined, although evidence is limited to retrospective studies including predominantly compensated (Child Pugh A) cirrhosis. ${ }^{24-26}$ In the largest of these, including 1267 patients with chronic liver disease, DPPB occurred in $0.7 \%$ with Child Pugh A but $4.4 \%$ of those with more advanced (Child Pugh $\mathrm{B}$ or C) cirrhosis. ${ }^{26}$ Patients with haematological disorders including von Willebrand disease and Haemophilia are well accepted to confer increased risk of bleeding during surgical procedures, although specific data in the context of polypectomy are limited, and may warrant prophylactic treatment with haemostatic agents and blood products. ${ }^{27}$

Broader descriptors of comorbidity including American Society of Anesthesiologists class have also not been associated with DPPB. ${ }^{13}$ Given that polypectomy is an elective procedure that may be deferred in sick patients, these data may be vulnerable to selection bias.

\section{Antithrombotics}

Antithrombotics are increasingly common in patients presenting for colonoscopy due to an ageing population with an increasing prevalence of cardiovascular and cerebrovascular disease. The risk of DPPB is affected by the following variables: a) the antithrombotic in question; b) duration withheld before polypectomy; c) duration withheld after polypectomy; and d) application of bridging therapy. These are discussed below. 
Table I Summary of Risk Factors for Delayed Post-Polypectomy Bleeding

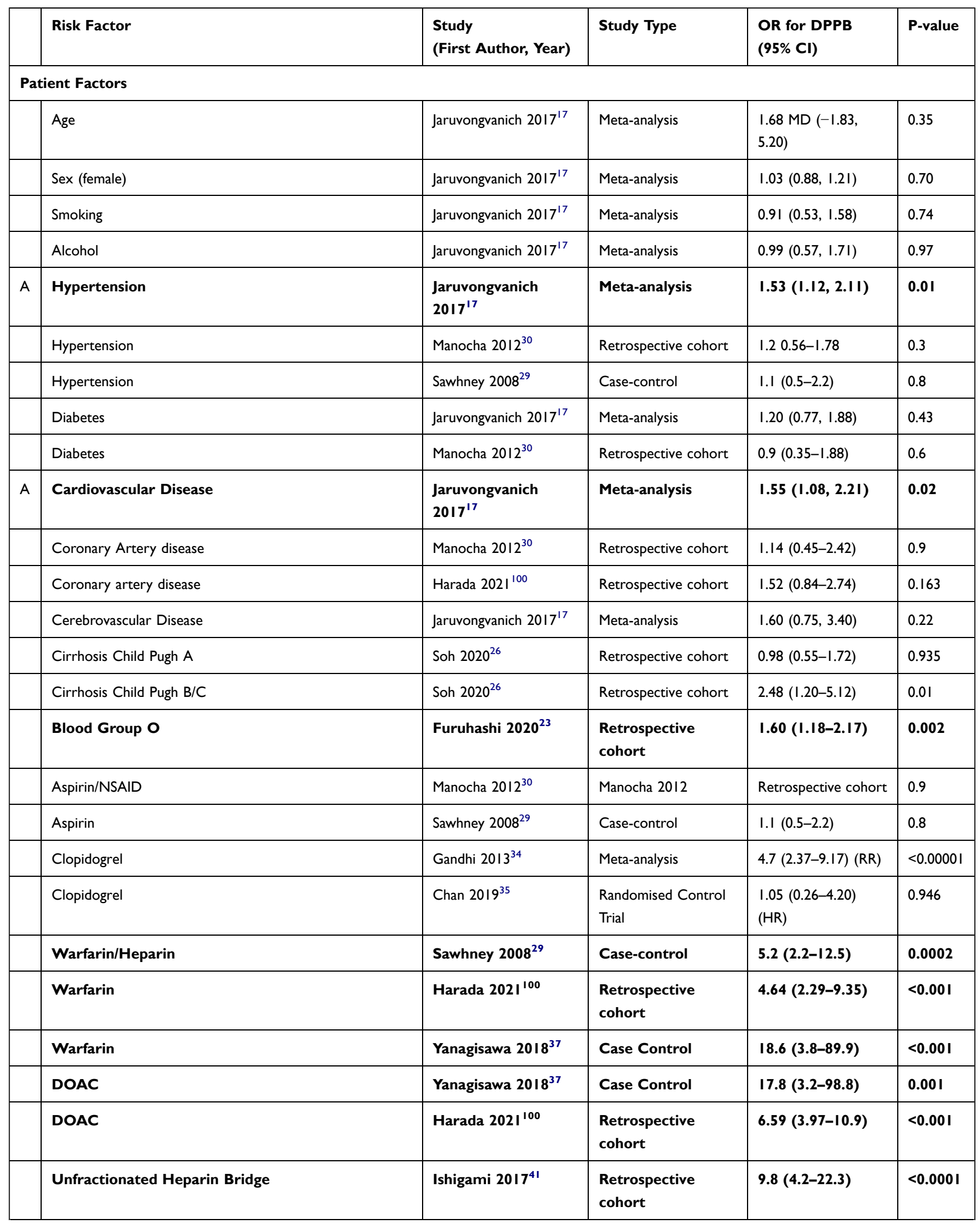

(Continued) 
Table I (Continued).

\begin{tabular}{|c|c|c|c|c|c|}
\hline & Risk Factor & $\begin{array}{l}\text { Study } \\
\text { (First Author, Year) }\end{array}$ & Study Type & $\begin{array}{l}\text { OR for DPPB } \\
(95 \% \mathrm{Cl})\end{array}$ & P-value \\
\hline \multicolumn{6}{|c|}{ Polyp Factors } \\
\hline \multirow[t]{2}{*}{ B } & Size Polyp I-2cm & Liu $2019^{99}$ & $\begin{array}{l}\text { Retrospective } \\
\text { cohort }\end{array}$ & $4.5(2.3-8.8)$ & $<0.001$ \\
\hline & Size $>10 \mathrm{~mm}$ & $\begin{array}{l}\text { Jaruvongvanich } \\
2017^{17}\end{array}$ & Meta-analysis & $3.41(2.55,4.56)$ & $<0.001$ \\
\hline B & Size Polyp 2-3cm & Liu $2019^{99}$ & Retrospective cohort & $4.0(0.9-17.8)$ & 0.068 \\
\hline \multirow[t]{7}{*}{ B } & Size Polyp $>3 \mathrm{~cm}$ & Liu $2019^{99}$ & $\begin{array}{l}\text { Retrospective } \\
\text { cohort }\end{array}$ & $22.4(5.8-86.8)$ & $<0.001$ \\
\hline & Location - Caecum & Rutter $2014^{45}$ & $\begin{array}{l}\text { Retrospective } \\
\text { cohort }\end{array}$ & $2.40(2.52-3.78)$ & $<0.001$ \\
\hline & Location - Right Colon & $\begin{array}{l}\text { Jaruvongvanich } \\
2017^{17}\end{array}$ & Meta-analysis & $1.6(1.12,2.30)$ & 0.01 \\
\hline & Morphology - Pedunculated & Jaruvongvanich $2017^{17}$ & Meta-analysis & $1.3(0.91,1.96)$ & 0.13 \\
\hline & Pathology (adenocarcinoma) & Jaruvongvanich $2017^{17}$ & Meta-analysis & $1.30(0.84,2.01)$ & 0.23 \\
\hline & Multiple Polyp Removal & Harada $2021^{100}$ & Retrospective cohort & $1.77(1.17-2.68)$ & 0.007 \\
\hline & Immediate post polypectomy bleeding & Zhang $2014^{47}$ & $\begin{array}{l}\text { Retrospective } \\
\text { cohort }\end{array}$ & $2.9(1.4-5.9)$ & 0.004 \\
\hline G & Immediate post polypectomy bleeding & Burgess $2014^{7}$ & Prospective cohort & $2.16(1.16-4.05)$ & 0.016 \\
\hline \multicolumn{6}{|c|}{ Procedural Factors } \\
\hline & Hot snare & Rutter $2014^{45}$ & $\begin{array}{l}\text { Retrospective } \\
\text { cohort }\end{array}$ & $2.02(1.30-3.14)$ & $<0.01$ \\
\hline G & $\begin{array}{l}\text { Non-microprocessor controlled electrosurgical } \\
\text { current }\end{array}$ & Burgess $2014^{7}$ & Prospective cohort & $2.03(1.04-3.95)$ & 0.038 \\
\hline C & Modality EMR & Liu $2019^{99}$ & Retrospective cohort & $9.1(3.5-23.5)$ & $P<0.001$ \\
\hline \multirow[t]{3}{*}{ C } & Modality ESD & Liu $2019^{99}$ & Retrospective cohort & $31.3(7.0-139.4)$ & $P<0.001$ \\
\hline & Submucosal adrenaline & Tullavardhana $2017^{79}$ & Meta-analysis & $0.45(0.11,1.81)$ & 0.26 \\
\hline & Routine Prophylactic clipping & Forbes $2019^{82}$ & Meta-analysis & $0.86(0.55$ to 1.36$)$ & 0.28 \\
\hline \multirow[t]{2}{*}{$\mathrm{D}$} & Prophylactic clip - proximal polyp & Yang $2021^{83}$ & Meta-analysis & $0.415(0.19-0.92)$ & 0.03 \\
\hline & Prophylactic clip - proximal polyp $>20 \mathrm{~mm}$ & Kamal 2020 & Meta-analysis & $\begin{array}{l}0.41(0.24,0.70) \\
(R R)\end{array}$ & 0.001 \\
\hline $\mathrm{E}$ & Prophylactic clip - distal polyp & Yang $2021^{83}$ & Meta-analysis & $1.16(0.295-4.571)$ & 0.83 \\
\hline \multirow[t]{2}{*}{$\mathrm{F}$} & Prophylactic electrocautery of resection defect & Lee $2019^{91}$ & $\begin{array}{l}\text { Randomised Control } \\
\text { Trial }\end{array}$ & $0.59(0.37-0.95)$ & 0.029 \\
\hline & $\begin{array}{l}\text { Endoscopist experience } \\
<300 \text { procedure count }\end{array}$ & Choung $2014^{61}$ & Retrospective cohort & $4.8(2.6-8.8)$ & $P=0.001$ \\
\hline
\end{tabular}

Notes: Studies in bold reflect statistically significant associations in the original literature. (A) Meta-analysis could not fully control for effect of antithrombotics. (B) Compared to Polyps < $<\mathrm{cm}$. (C) Compared to argon plasma coagulation. (D) Proximal colon polyp represents polyp located at cecum, ascending colon, or hepatic flexure. (E) Distal colon polyp represents polyp located at transverse colon, splenic flexure, descending colon, sigmoid colon, or rectum. (F) Electrocautery applied to visible vessels and erythema using coagulation probe, sessile polyps $>10 \mathrm{~mm}$. (G) Lateral spreading lesions $\geq 20 \mathrm{~m}$ following wide field EMR.

Abbreviations: $M D$, mean difference; RR, relative risk; HR, hazard ratio. 


\section{Aspirin}

Aspirin has repeatedly been shown to be safe in colonoscopy polypectomy, ${ }^{28-30}$ including resection of large nonpedunculated colorectal polyps with EMR. ${ }^{13}$ Weighed against this are the risks of aspirin interruption with a meta-analysis highlighting a threefold risk of major adverse cardiac events following aspirin non-adherence or withdrawal. ${ }^{31}$ International societies therefore recommend uninterrupted aspirin therapy for polypectomy. ${ }^{32,33}$

\section{Clopidogrel}

Clopidogrel and other $\mathrm{P}_{2} \mathrm{Y}_{12}$ receptor modulators including ticagrelor and prasugrel are commonly co-prescribed with aspirin in high-risk patients following acute coronary syndrome. Clopidogrel monotherapy is also prescribed for secondary prevention of cerebrovascular or peripheral vascular disease. The overall quality of evidence regarding the risk of post-polypectomy bleeding with clopidogrel is poor, reflecting retrospective study designs mainly assessing small polyps with heterogeneous populations that include aspirin co-prescription.

Given the thrombotic risk associated with clopidogrel interruption in high-risk indications (eg, within 3 months after percutaneous intervention with drug-eluting stents), recent studies have advocated for uninterrupted clopidogrel therapy. A meta-analysis of five observational studies, comprising 574 patients, concluded that uninterrupted clopidogrel therapy increased the risk of DPPB (RR 4.66; 95\% CI $2.37-9.17 ; \mathrm{p}<0.0001)$ but not immediate postpolypectomy bleeding. ${ }^{34}$ In a recent randomised controlled trial (RCT), uninterrupted clopidogrel was not associated with a significant risk of post polypectomy bleeding, however $90 \%$ of polyps included were $<10 \mathrm{~mm}$ in size ${ }^{35}$ Based on this, recent BSG/ESGE guidelines advise that if it is not appropriate to defer the procedure, with caution it may be safe to undertake polypectomy of polyps $<1 \mathrm{~cm}$ whilst on clopidogrel monotherapy, or to temporarily switch to aspirin for 7 days in advance of the procedure. ${ }^{32}$

\section{Anticoagulants}

There is a paucity of RCT data on the safety of polypectomy with regard to warfarin and direct oral anticoagulants (DOACs). ${ }^{32}$ DOACs are increasingly being prescribed instead of warfarin due to their non-inferiority, convenience, safety profile and with a widening spectrum of indications. Their rapid onset of action has particular relevance for DPPB.
A retrospective cohort study, where warfarin was commonly stopped 4 days before and resumed in the evening following colonoscopy, was still associated with increased risk of DPPB (AOR 11.6; 95\% CI 2.3-57.3). ${ }^{36}$ This is consistent with another retrospective study that where the recommencement of anticoagulation (warfarin or heparin) within one week following polypectomy was associated with an increased risk of post-polypectomy bleeding (OR 5.2; 95\% CI 2.2-12.5; $\mathrm{P}<0.001) .{ }^{29}$ When comparing warfarin and DOAC users, a retrospective single centre study in Japan including 31.7\% polyps $>10 \mathrm{~mm}$ identified similarly high post-polypectomy bleeding rates in both groups, compared with controls (13.7\% vs $0.9 \%, \mathrm{P}<0.001) .{ }^{37}$ A retrospective case-matched analysis comparing DOACs to clopidogrel in patients undergoing polypectomy of predominantly $<10 \mathrm{~mm}$ polyps identified no difference in DPPB which occurred in 3\% in both groups. ${ }^{38}$ Prophylactic clipping was more commonly performed in the DOAC group. ${ }^{38}$ Within the DOAC class, apixaban has been associated with a lower risk of post polypectomy bleeding than rivaroxaban, dabigatran and warfarin. ${ }^{39}$

The use of bridging anticoagulation, typically with low molecular weight heparin (LMWH) or sometimes unfractionated heparin (UFH), is used when patients on warfarin pose a high risk of thromboembolism. ${ }^{32}$ Both methods have been associated with increased rates of clinically significant $\mathrm{DPPB},{ }^{40}$ with rates for UFH as high as $22.2 \%$ (OR 9.80; 95\% CI 4.23-22.3; $\mathrm{P}<0.0001$ ) in one retrospective study, regardless of polyp size. ${ }^{41}$

\section{Polyp Factors}

Size

Polyp size is the single most important polyp-related factor that has been consistently demonstrated to affect DPPB. ${ }^{17,42}$ This correlation was analysed in a meta-analysis in 2017 , by Jaruvongvanich et al, ${ }^{17}$ where a polyp size of $\geq 10 \mathrm{~mm}$ was associated with a 3.4-fold risk of DPPB. Subsequent to this, a retrospective study looking at colonic endomucosal resection identified each additional $1 \mathrm{~mm}$ increased bleeding risk by an estimated $8 \%$ on multivariate analysis, ${ }^{20}$ in line with previous studies..$^{29,42,43}$

When considering very large polyps $(\geq 40 \mathrm{~mm})$, another retrospective study found that patients who did and did not experience post-EMR bleeding differed only in the size of the lesion resected $(43.2 \pm 3.6 \mathrm{~mm}$ vs $17.5 \pm 10.3 \mathrm{~mm}, \mathrm{P}<$ $0.001) .{ }^{44}$ For polyps $\geq 40 \mathrm{~mm}$ in diameter, the risk of postEMR bleeding increased 43 -fold compared to those $<40 \mathrm{~mm}$. 


\section{Location}

Polyp location poses a number of site-specific considerations for an endoscopist and this includes the risk of DPPB. Polypectomy in the right colon, especially the caecum, has been identified as an important risk factor. A large observational study of a national bowel screening programme cohort, after adjusting for polyp size, identified the caecal location conferred a 14-fold risk of DPPB. ${ }^{45}$ This is supported by meta-analysis data associating right-sided polypectomy with DPPB $(\mathrm{OR}=1.60 \%$, 95\% CI 1.12-2.30). ${ }^{17}$ The underlying mechanism for this is unclear but may be due to difference in wall thickness and response to submucosal injection, exposure to ileal fluids, as well as difficult endoscope position. ${ }^{42}$

\section{Morphology}

Polyp morphology has been extensively investigated with variable results. Whilst sessile polyps may have greater potential for submucosal vessel injury due to depth of resection specimen, other retrospective studies have observed more cases of DPPB in patients with pedunculated polyps. Large calibre vessels in the polyp stalk can result in both immediate and DPPB. Stalk diameter of $>5 \mathrm{~mm}$ has been shown to be a risk factor for DPPB (OR 7.17 (95\% CI 5.97-8.61) $\mathrm{P}<0.001){ }^{46}$

In the meta-analysis by Jaruvongvanich et al, pedunculated polyps were not associated with DPPB (OR $1.34(0.91,1.96)$ $\mathrm{P}$ value 0.13$).{ }^{17}$ Large retrospective studies since this metaanalysis have shown similar non-significant association. ${ }^{20}$

\section{Histopathology}

Polyp pathology with the presence of adenocarcinoma was not associated with DPPB in a meta-analysis, ${ }^{17}$ although a large retrospective cohort, included within the meta-analysis, did identify both hamartomatous juvenile (OR 5.7) and Peutz-Jeghers (OR 4.3) polyps to have increased risks of DPPB, when compared to inflammatory/hyperplastic polyps. ${ }^{47}$

\section{Resection Technique}

Many of the patient and polyp factors mentioned above will impact the endoscopist decision regarding the method of polypectomy. The ESGE guidelines contain clear recommendations on endoscopic resection techniques based on polyp size and morphology. ${ }^{11}$ The spectrum of techniques including hot and cold snare polypectomy, endoscopic mucosal resection and endoscopic submucosal resection have been assessed for risk of DPPB, although their effect is often confounded by polyp size and morphology. Full thickness endoscopic resection and surgical hybrid resection techniques lie beyond the scope of this review.

Small polyps less than $10 \mathrm{~mm}$ are typically removed either by hot snare polypectomy (HSP) or cold snare polypectomy (CSP), and are both effective in achieving low levels of residual polyp tissue. ${ }^{48}$ HSP remains the primary method for resection of large sessile lesions $>10 \mathrm{~mm}$ as well as pedunculated polyps.

With larger non-pedunculated colorectal polyps $(>20 \mathrm{~mm})$, alternate modalities including EMR and ESD are increasingly used. Bleeding is the most common complication of EMR, and large cohorts report a typical incidence between $2 \%$ and $7 \%{ }^{49-51}$ A large recent systematic review by Hassan et al of 6779 large polyps $>20 \mathrm{~mm}$, in 50 studies, identified DPPB in $2.6 \%$ (95\% CI 2.1\%-3.2). ${ }^{52}$ Modified techniques, including underwater EMR (UEMR), are increasingly used with the aim of facilitating complete en-bloc resection. ${ }^{53-55}$ It is thought that UEMR allows the mucosa and submucosa to float away from the muscularis propria, ${ }^{56}$ while water provides a heat sink effect during diathermy that prevents deep thermal injury. ${ }^{57}$ However, recent RCTs and meta-analysis comparing underwater EMR with conventional EMR did not identify any difference between rates of DPPB. ${ }^{55,58,59}$

A meta-analysis of 6 non-randomised studies compared the rate of DPPB after EMR and ESD. ${ }^{51}$ The overall rate of DPPB in the EMR group was 3.5\%, whereas that in the ESD group was only $2.0 \%$, despite increased tumour size in the ESD groups.

Modern day electrosurgical units are equipped with microprocessors that enable automated delivery of current in response to tissue resistance, which varies with a number of polypectomy-associated variables, eg, snare thickness, polyp diameter, tension of snare closure, etc. The use of an electrosurgical current not controlled by a microprocessor has been shown to increase DPPB (OR 2.03; P $=0.038){ }^{7}$ The optimal mode of diathermy for large non-pedunculated polyps, ie, the use of blended current (yellow pedal) vs coagulation (blue pedal), has long been debated. The recent landmark RCT by Pohl et al compared Endocut vs forced coagulation for the resection of large non-pedunculated colorectal polyps and found no difference in serious adverse event rates including DPPB (5.0\% vs $5.7 \%$ respectively). ${ }^{60}$

\section{Immediate Post-Polypectomy Bleeding}

Immediate post-polypectomy bleeding, while beyond the scope of this review, is a risk factor for DPPB. The large 
retrospective cohort by Zhang et al identified immediate bleeding to be a significant risk factor (OR 2.9; 95\% CI $1.4-5.9 ; \mathrm{p}=0.004),{ }^{47}$ with Burgess et al reporting a similar effect $(\mathrm{OR} 2.16 ; \mathrm{P}=0.016){ }^{7}$ These results were replicated in a case control study, ${ }^{18}$ where the need for additional conscious sedation, suggesting a more difficult colonoscopy, was also associated with DPPB.

\section{Personnel Related Factors}

In addition to the choice and technique of polyp resection (which are endoscopist-dependent), another important consideration is that of personnel including endoscopist experience and the assisting team.

Different measures have been assessed to act as surrogate for colonoscopist expertise. A time-based split between endoscopists with greater or less than 10 years experience identified no significant difference in a retrospective cohort. ${ }^{20} \mathrm{~A}$ greater difference was noted when assessing numerical experience. A retrospective review of 5981 polypectomies identified that a colonoscopy procedure count less than 300 was a significant risk factor for DPPB (OR 4.8; $95 \%$ CI $02.6-8.8 ; \mathrm{p}=0.001) .{ }^{61} \mathrm{~A}$ recent meta-analysis, limited by study heterogeneity, which evaluated annual colonoscopy volume and colonoscopy quality found a nonsignificant trend towards decreased overall adverse events with each additional 100 annual procedures (OR 0.95; 95\% CI $0.90-1.00){ }^{62}$ As well as its primary importance as a risk factor, it is important to note the potential for endoscopic expertise to act as an important confounding factor, when not detailed in individual study methodology.

Non-technical skills including leadership, judgement, teamwork and situational awareness are now well recognised to contribute to safe and effective patient care, and are becoming embedded into endoscopy training programmes. ${ }^{63}$ Further studies are needed to show benefit for patient outcomes specific to colonoscopy including DPPB.

\section{Reducing the Risk of DPPB}

The identification of risk factors that contribute to DPPB should be applied at a patient level to identify high-risk patients, and implement strategies to mitigate such risk where possible. A summary of proposed intervention, stratified by a patient's journey before, during and after endoscopy

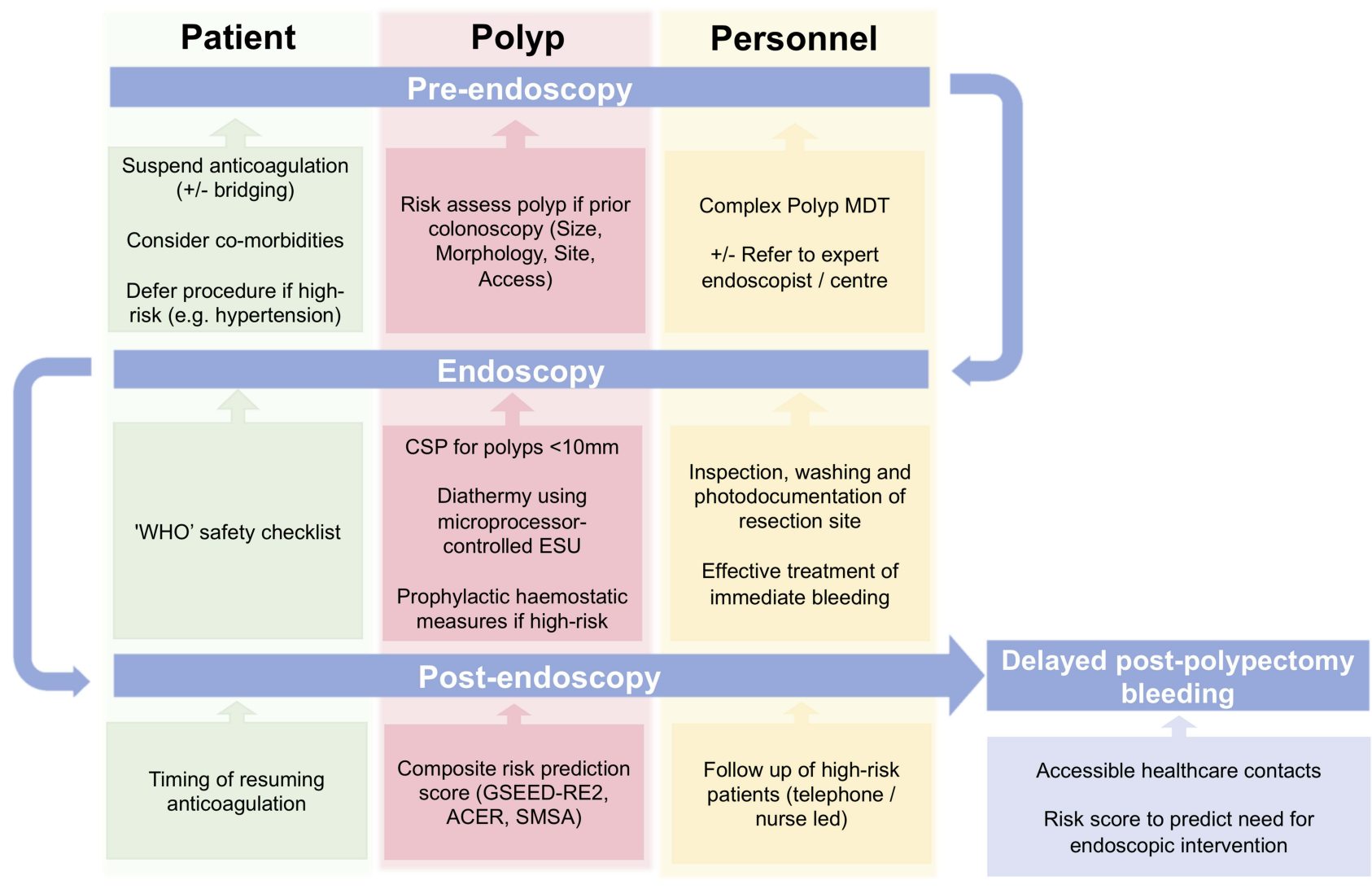

Figure 2 Timeline summary of strategies to minimise impact of delayed post polypectomy bleeding. 
is presented below and summarised in Figure 2. Many of these interventions may be considered generic and do not necessarily have the primary aim to reduce DPPB, or the accompanying evidence base, but rather form part of a broader aim to improve the patient experience and reduce adverse events.

\section{Pre-Endoscopy}

\section{Pre-Procedure Planning}

An important primary consideration is timing of the procedure. In certain cases, for example patients on dual or triple antithrombotic therapy following a recent acute coronary syndrome, it may be prudent to delay planned polypectomy until that risk is minimised. ${ }^{32,64}$ Consultation with cardiology or relevant specialties is universally advised.

Pre-endoscopy planning for polyp resection is also encouraged. Whilst screening colonoscopies may require the endoscopist to make a peri-procedural decision regarding resection appropriateness and technique, in many circumstances a prior colonoscopy has already been undertaken. Complex polyps, which can be identified using composite scoring systems such as the "SMSA" scoring system may warrant referral to an individual or specialist centre with relevant expertise. ${ }^{65}$ Whilst such decisions can be made by an individual endoscopist, decision-making can be more accountable when made through a multidisciplinary team, so-called "Complex Polyp MDT", 66 although specific evidence of benefit in the context of adverse events including DPPB has not yet been demonstrated.

\section{Optimisation of Anticoagulation Status}

Given the presence of anticoagulation is a significant risk factor for DPPB, when to stop, and particularly when to resume antithrombotics, is an important consideration. Inherently, earlier restart of anticoagulants confers greater bleeding risk, with resumption of warfarin within 72 hours after a polypectomy associated with a five-fold increased risk of DPPB. ${ }^{29}$ However, this must be weighed against the risk of thrombosis. Based on this balance of risk, international societies provide guidance on the resumption of anticoagulation (Table 2), however there is little highquality evidence to guide timing of resumption, particularly of DOACs.

A large prospective cohort study has confirmed the safety of foregoing bridging therapy for patients with atrial fibrillation on DOAC therapy, with low rates of both major bleeding $(<2 \%)$ and stroke $(<1 \%)$ when DOACs were introduced 48 to 72 hours post operatively. ${ }^{67}$

\section{During Endoscopy Use of Safety Checklists}

On the day of endoscopy, it is important to review preprocedure information to ensure the right procedure has been planned safely on the right patient. The WHO Safer Surgical Checklist with a dedicated "time out" immediately before starting the procedure has been shown to reduce error and mortality in surgery. ${ }^{68}$ Such structured checklists are well established within endoscopy, although further evidence is required to demonstrate improved outcomes specific to DPPB. ${ }^{69,70}$

\section{Emergence of Cold Snare Polypectomy}

Recent years have seen a marked shift away from HSP in favour of limiting thermal injury by using cold snare polypectomy. Chang et al found that implementation of CSP in a screening setting for small and diminutive polyps $(4-10 \mathrm{~mm})$ resulted in significant reductions in DPPB $(0.1 \%$ vs $1.1 \%$ for HSP; $\mathrm{P}<0.001)$, serious DPPB $(0 \%$ vs $0.7 \% ; \mathrm{P}<0.01)$ and emergency hospitalization $(0.1 \%$ vs $1.0 \%$; $<<0.01) .^{71}$ The CRESCENT RCT compared CSP vs HSP for 4-9mm colorectal polyps found higher complete resection rates with CSP $(98.2 \%$ vs $97.4 \%, \mathrm{P}<$ $0.001),{ }^{72}$ with DPPB only occurring in the HSP groups $(0.5 \%)$. An RCT of anticoagulated patients found HSP to be associated with a significantly higher rate of DPPB compared to CSP (14\% vs $0 \%$; p 0.027). ${ }^{73}$ This study and seven other randomised control trials were analysed in a meta-analysis by Shinozaki et al in 2018; whilst HSP was associated with a higher rate of DPPB (risk ratio 7.53; 95\% CI 0.94-60.24), the result did not meet significance $(\mathrm{P}=0.06){ }^{48}$ There are other benefits to CSP including shorter procedure time, cost saving and reduced incidence of post-polypectomy syndrome that place CSP as the preferred method for small polyp excision. ${ }^{48,74}$

The application of diathermy-free techniques extends into the large sessile polyps, where cold EMR has demonstrated a comparable safety profile. $^{75}$ A retrospective review of piecemeal cold snare EMR of 204 sessile nonmalignant polyps sized $\geq 20 \mathrm{~mm}$ reported a comparable DPPB rate of $3.8 \%{ }^{76}$

Prophylactic Endoscopic Techniques to Reduce DPPB Beyond the broader choices for endoscopic resection outlined previously, there are a number of additional 
Table 2 Summary of International Society Regarding Resumption of Anticoagulants Following High-Risk Procedures Including Polypectomy

\begin{tabular}{|c|c|c|c|}
\hline Society & Year & Warfarin & DOAC \\
\hline BSG/ESGE ${ }^{32}$ & 2021 & $\begin{array}{l}\text { Low thrombotic risk: } \\
\text { Restart warfarin usual daily dose } \\
\text { evening of procedure. } \\
\text { INR I week later } \\
\text { High thrombotic risk: } \\
\text { Restart warfarin usual daily dose } \\
\text { at night. } \\
\text { Bridging therapeutic dose LMWH } \\
\text { (held on the day of procedure) to } \\
\text { restart the day after. } \\
\text { Continue LMWH until } \\
\text { a satisfactory INR is achieved. }\end{array}$ & $\begin{array}{l}\text { All thrombotic risk groups } \\
\text { Restart DOAC } 2-3 \text { days after procedure, depending on } \\
\text { hemorrhagic and thrombotic risk } \\
\text { No heparin bridging } \\
\text { Consider extended interval for ESD }\end{array}$ \\
\hline $\mathrm{ASGE}^{33}$ & 2016 & $\begin{array}{l}\text { Low CV risk } \\
\text { Restart warfarin on same day of } \\
\text { procedure } \\
\text { High CV Risk } \\
\text { Restart warfarin on same day of } \\
\text { procedure } \\
\text { Bridging therapy (UFH or } \\
\text { LMWH) until INR therapeutic } \\
\text { The optimal time to restart } \\
\text { LMWH after endoscopy has not } \\
\text { been determined }\end{array}$ & $\begin{array}{l}\text { Low CV Risk } \\
\text { Delay reinitiating NOACs until adequate hemostasis is } \\
\text { achieved } \\
\text { High CV Risk } \\
\text { Delay reinitiating NOACs until adequate hemostasis is } \\
\text { achieved } \\
\text { If therapeutic doses of NOACs cannot be restarted } \\
\text { within } 12 \text { to } 24 \text { hours after a high-risk endoscopic } \\
\text { procedure, thromboprophylaxis (ie, UFH bridge) should } \\
\text { be considered }\end{array}$ \\
\hline $\begin{array}{l}\text { Asian Pacific Association of } \\
\text { Gastroenterology/Asian Pacific Society of } \\
\text { Digestive Endoscopy (APAGE/APSDE) }\end{array}$ & 2017 & $\begin{array}{l}\text { Low thrombotic risk } \\
\text { Resume warfarin after adequate } \\
\text { haemostasis } \\
\text { No heparin bridging } \\
\text { High thrombotic risk } \\
\text { Resume warfarin after adequate } \\
\text { haemostasis } \\
\text { Heparin bridging } \\
\text { Very high thrombotic risk } \\
\text { (ACS/PCI <6 weeks) } \\
\text { Defer procedure }\end{array}$ & $\begin{array}{l}\text { All thrombotic risk groups } \\
\text { Resume DOACs when adequate haemostasis is } \\
\text { achieved } \\
\text { No heparin bridging }\end{array}$ \\
\hline
\end{tabular}

techniques that can be considered in order to reduce the risk of DPPB. Such techniques include pre-treatment of pedunculated polyp stalks, defect closure with prophylactic clip placement and endotherapy to the mucosal defect.

Pedunculated polyps are typically removed from the stalk base using a hot snare. Bleeding is the most common adverse event. Randomised control trials have assessed the respective merits of prophylactic adrenaline and mechanical clip placement for pedunculated polyps. Individual RCTs have shown benefit of pretreatment of larger pedunculated polyp stalks with adrenaline. ${ }^{77,78}$ A subsequent meta-analysis of six RCTs, which did not distinguish between sessile and pedunculated polyps in its final analysis, found submucosal injection of adrenaline reduced the occurrence of early bleeding but did not affect DPPB. ${ }^{79}$ Further RCTs have demonstrated superiority of mechanical haemostasis with either clip or detachable snare (with or without adrenaline), over adrenaline alone. $^{80,81}$ For this reason, ESGE recommends pretreatment of pedunculated polyps, with heads $>20 \mathrm{~mm}$ or stalk $>10 \mathrm{~mm}$, with injection of dilute adrenaline and/or mechanical haemostasis. ${ }^{11}$

The question of when to apply prophylactic closure of a mucosal defect after polypectomy is controversial. 
A recent meta-analysis of $7 \mathrm{RCTs}$, including 24\% polyps $>10 \mathrm{~mm}$, did not identify any overall benefit for clipping in preventing DPPB, but was underpowered to identify differences in subgroups such as polyp location and size. ${ }^{82}$ This has been addressed in subsequent meta-analyses of large non-pedunculated lesions where clip closure for polyps $>20 \mathrm{~mm}$ situated in the proximal colon reduced DPPB by over $50 \% .^{83-85}$ In a decision analysis, Parikh et al concluded that prophylactic clip placement was costeffective for $10-15 \mathrm{~mm}$ polyps in patients on non-aspirin antithrombotic therapy, ${ }^{86}$ although their model assumed a $82 \%$ risk reduction rate in DPPB. It should also be noted that any benefit with clips is dependent on successful closure of the defect, which may not be achievable or incomplete in $30-40 \%$ cases. ${ }^{87,88}$ Current ESGE guidelines do not recommend routine clip closure but leave it for the discretion of the endoscopist in higher-risk cases. ${ }^{11}$

\section{Inspection of Resection Site}

Close attention to the residual mucosal defect is important to assess adequacy of resection and assess for complications such as bleeding and perforation. ${ }^{89}$ A prospective audit of piecemeal-EMR found that visible muscle fibers and the presence of a "cherry red spot" was associated with DPPB, whereas visible intact vessels and the use of argon plasma photocoagulation was not. ${ }^{13}$ Close observation of the defect and prompt management of immediate bleeding can prevent DPPB. This is supported by a retrospective study that involved close inspection and irrigation of the resection site, with a haemostatic clip placed if any bleeding persisted for more than 30 seconds, which resulted in a decreased incidence of DPPB $(0.4 \%)$ compared with controls $(1.1 \%){ }^{90}$

A recent RCT assessed prophylactic endoscopic coagulation to reduce DPPB following EMR of sessile polyps greater than $>10 \mathrm{~mm}$. Five hundred and seventy patients were randomised following resection to either usual care or prophylactic electrocautery (PEC) until visible vessels or erythema disappeared. PEC was associated with significantly decreased risk of DPPB. ${ }^{91}$ Alternatives to PEC are also being investigated. A recent RCT by Subramaniam et al assessed the application of a topical haemostatic matrix, Purastat (3DMatrix Europe Ltd., France) during ESD of oesophageal and colonic lesions $2-5 \mathrm{~cm}$, compared with usual electrocautery. The Purastat group was associated with improved wound healing at 4 weeks and no significant difference in rate of DPPB $(4.3 \%$ vs $4.4 \% ; p=0.98) .{ }^{92}$

\section{Post-Endoscopy}

Risk Scores to Predict Post-Polypectomy Bleeding

Quantifying the risk of DPPB using an evidence-based approach can help to tailor a patient's pre-procedural, intraprocedural and post-procedural management. A number of risk scores have been devised for this purpose, which are summarised in Table 3.

In 2016, both an Australian (ACER score) and a Spanish group (GSEED-RE score) published risk scores that predicted DPPB in patients undergoing EMR of sessile lesions $\geq 20 \mathrm{~mm} .{ }^{93,94}$ The ACER score comprised four risk components; lesion size $>30 \mathrm{~mm}$, proximal colon location, presence of major comorbidity and adrenaline not being used. ${ }^{93}$ Components of these risk scores overlapped, and subsequently in 2019 the Spanish group internally revalidated their score, combining it with the ACER score to produce the GSEEDRE2. ${ }^{95}$ The GSEED-RE2 includes 4 components; antiplatelets or anticoagulants ( 3 points), proximal location ( 3 points), size $\geq 40 \mathrm{~mm}$ ( 2 points) and ASA III/IV comorbidity ( 1 point). The compiled score is stratified into low risk $(0-3)$, medium risk (4-6), high risk (7-9) groups, and corresponded with a DPPB bleeding risk of $2.2 \%, 4.1 \%$ and $14.8 \%$, respectively. Unlike the previous iterations, the GSEED-RE2 has the benefit that it can be calculated prior to endoscopy.

The "SMSA" classification system has also been studied in the context of adverse events including DPPB. A retrospective review of a database of large colonic laterally spreading lesions (LSLs) $\geq 20 \mathrm{~mm}$ found clinically significant post-polypectomy bleeding was significantly less common for SMSA 2 LSLs (OR 0.23, P $<0.01)$ and SMSA 3 LSLs

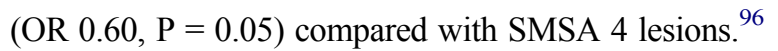

Of note, neither the commonly used CHADSVASC nor HASBLED scores predicted $\mathrm{PPB}$ in one retrospective cohort, most likely reflecting the primary importance of polyps factor in the risk of DPPB. ${ }^{40}$

\section{Recognition and Treatment of Delayed Post-Polypectomy Bleeding}

Given nearly all patients undergoing polypectomy will be discharged on the day of the procedure, it is vital patients are provided with information of symptoms suggestive of DPPB, and how to best seek medical advice.

Whilst mortality from DPPB is extremely low, patients typically require hospitalisation for clinical assessment, consideration of transfusion and further endoscopic 
Table 3 Summary of Risk Scores to Predict Delayed Post-Polypectomy Bleeding Following EMR

\begin{tabular}{|l|l|l|l|}
\hline Risk Score & $\begin{array}{l}\text { Author \& } \\
\text { Year }\end{array}$ & Study Population & Components \\
\hline $\begin{array}{l}\text { Size, Morphology, Site, and Access score } \\
\text { "SMSA" }\end{array}$ & Sidhu 201796 & $\begin{array}{l}\text { Lateral spreading lesions } \\
\geq 20 \mathrm{~mm} \\
\text { EMR }\end{array}$ & $\begin{array}{l}\text { Size: graded score } \\
\text { Morphology: pedunculated, sessile, flat } \\
\text { Site: left colon, right colon } \\
\text { Access: easy, difficult }\end{array}$ \\
\hline $\begin{array}{l}\text { Australian Colonic Endoscopic Resection } \\
\text { "ACER" }\end{array}$ & Bahin 201693 & $\begin{array}{l}\text { Lateral spreading lesions } \\
\geq 20 \mathrm{~mm} \\
\text { EMR }\end{array}$ & $\begin{array}{l}\text { Lesion size } \geq 30 \mathrm{~mm} \\
\text { Location: proximal colon } \\
\text { Co-morbidity } \\
\text { Absence of epinephrine use }\end{array}$ \\
\hline GSEED-RE & $\begin{array}{l}\text { Albéniz } \\
2016^{94}\end{array}$ & $\begin{array}{l}\text { Non-pedunculated } \\
\text { EMR }\end{array}$ & $\begin{array}{l}\text { Age: }<75, \geq 75 \\
\text { ASA: I-II, III-IV } \\
\text { Size: }>40 \mathrm{~mm},<40 \mathrm{~mm} \\
\text { Aspirin } \\
\text { Complete closure } \\
\text { Location: Proximal to transverse colon }\end{array}$ \\
\hline GSEED-RE2 & $\begin{array}{l}\text { Albéniz } \\
2019^{95}\end{array}$ & $\begin{array}{l}\geq 20 \mathrm{~mm} \\
\text { EMR }\end{array}$ & $\begin{array}{l}\text { Non-pedunculated colorectal lesions } \\
\text { ASA: III-IV } \\
\text { Lesion size } \geq 40 \mathrm{~mm} \\
\text { Location: Proximal to transverse colon } \\
\text { Antiplatelet or anticoagulant use }\end{array}$ \\
\hline
\end{tabular}

intervention or surgery. In a large cohort from the UK Bowel Cancer Screening programme including 11,564 patients, there was no mortality from DPPB, but $27.9 \%$ underwent repeat endoscopy, $13.2 \%$ received a blood transfusion and $1.5 \%$ required surgery. ${ }^{45}$ Median hospital stay was 2 days. ${ }^{45}$ Notably, in this cohort, less than half of the patients who underwent repeat colonoscopy received endoscopic therapy during the procedure. This is similar to a recent multi-centre cohort where $43 \%$ did not require therapy. ${ }^{97}$ Predictors of the need for endoscopic intervention were active use of anticoagulation, left-sided polyps, prior electrocautery and pedunculated morphology. ${ }^{97}$

Within the field of EMR, Burgess et al proposed a management algorithm for DPPB including predictors of need for intervention. Predictors for urgent intervention included the need for transfusion, haemoglobin $<12 \mathrm{~g} / \mathrm{dL}$ on admission, haemodynamic instability, ongoing hematochezia and American Society of Anesthesiologists grade $\geq 2 .{ }^{98}$

\section{Future Directions}

The last few decades have already seen the incidence of DPPB decrease, despite the increasing complexity of polypectomy undertaken. ${ }^{10}$ This is likely multifactorial due to improving endoscopic techniques, the emergence of cold snare polypectomy and changes in anticoagulation use with the advent of DOACs. ${ }^{39}$ Further reduction in the incidence of DPPB should occur as part of a broader aim to improve colonoscopy practise.

The low incidence of post-polypectomy bleeding can be a barrier for designing high-quality, adequately powered studies, and reinforces the ongoing benefit of collaborative multi-centre work and data from large screening populations. Further large studies will likely refine the area of current practice, for example guiding approaches to the optimal timing resumption of anticoagulants including DOACs.

A key challenge is how best to transfer the knowledge gained from large population studies and apply it to the next individual patient, in order to provide accurate and helpful prognostic information of risk. Risk scores, so far seen predominantly within the field of EMR, are an important step in this direction, but require further validation and care to avoid increasing score complexity that may limit practical use. Artificial intelligence and machine learning may have a role in bridging this gap. A large number of patient, polyp and procedure factors could be compiled into an individual risk score. Equally, artificial intelligence may have a role in review of residual resection sites of larger defects, to help identify residual polyp, direct 
prophylactic endotherapy and personalise antithrombotic management in patients at high risk of DPPB.

\section{Conclusion}

DPPB is a primary complication of colonoscopy and its frequency increases with the complexity of polypectomy. Numerous patient, polyp and personnel related risk factors contribute to the risk of DPPB. Overall, the greatest risks are seen with the presence of antithrombotics, increasing polyp size, proximal polyp location and use of thermal energy.

Interventions to reduce risk and impact of DPPB include an increasing array of endoscopic techniques, but attention must also be made to pre- and post-procedure care. Although composite risk scores for DPPB exist, future advances may include the use of artificial intelligence to improve risk prediction and individualize antithrombotic management.

\section{Disclosure}

JAT has received fees for the following: consultant for Conmed; consultant and speaker for Cook Medical. All other authors report no conflicts of interest in this work.

\section{References}

1. Shaukat A, Mongin SJ, Geisser MS, et al. Long-term mortality after screening for colorectal cancer. $N$ Engl J Med. 2013;369 (12):1106-1114. doi:10.1056/NEJMoa1300720

2. Cardoso R, Niedermaier T, Chen C, Hoffmeister M, Brenner $H$. Colonoscopy and sigmoidoscopy use among the average-risk population for colorectal cancer: a systematic review and trend analysis. Cancer Prev Res. 2019;12(9):617-630. doi:10.1158/1940-6207.CAPR-19-0202

3. Ishaq S, Siau K, Harrison E, et al. Technological advances for improving adenoma detection rates: the changing face of colonoscopy. Dig Liver Dis. 2017;49(7):721-727. doi:10.1016/j.dld.2017.03.030

4. Kim SY, Kim H-S, Park HJ. Adverse events related to colonoscopy: global trends and future challenges. World J Gastroenterol. 2019;25 (2):190-204. doi:10.3748/wjg.v25.i2.190

5. Nelson DB, McQuaid KR, Bond JH, Lieberman DA, Weiss DG, Johnston TK. Procedural success and complications of large-scale screening colonoscopy. Gastrointest Endosc. 2002;55(3):307-314. doi:10.1067/mge.2002.121883

6. Amato A, Radaelli F, Dinelli M, et al. Early and delayed complications of polypectomy in a community setting: the SPoC prospective multicentre trial. Dig Liver Dis. 2016;48(1):43-48. doi:10.1016/j. dld.2015.09.007

7. Burgess NG, Metz AJ, Williams SJ, et al. Risk factors for intraprocedural and clinically significant delayed bleeding after wide-field endoscopic mucosal resection of large colonic lesions. Clin Gastroenterol Hepatol. 2014;12(4):651-661.e1-e3. doi:10.1016/j.cgh.2013.09.049

8. Rex DK, Schoenfeld PS, Cohen J, et al. Quality indicators for colonoscopy. Gastrointest Endosc. 2015;81(1):31-53. doi:10.1016/j. gie.2014.07.058

9. Shaukat A, Holub J, Pike IM, et al. Benchmarking adenoma detection rates for colonoscopy: results from a US-based registry. $A C G$. 2021;116(9):1946.
10. Reumkens A, Rondagh EJA, Bakker CM, Winkens B, Masclee AAM, Sanduleanu S. Post-colonoscopy complications: a systematic review, time trends, and meta-analysis of population-based studies. Am $J$ Gastroenterol. 2016;111 (8):1092-1101. doi:10.1038/ajg.2016.234

11. Ferlitsch M, Moss A, Hassan C, et al. Colorectal polypectomy and endoscopic mucosal resection (EMR): European Society of Gastrointestinal Endoscopy (ESGE) Clinical guideline. Endoscopy. 2017;49(3):270-297. doi:10.1055/s-0043-102569

12. Rees CJ, Thomas Gibson S, Rutter MD, et al. UK key performance indicators and quality assurance standards for colonoscopy. Gut. 2016;65(12):1923-1929. doi:10.1136/gutjnl2016-312044

13. Elliott TR, Tsiamoulos ZP, Thomas-Gibson S, et al. Factors associated with delayed bleeding after resection of large nonpedunculated colorectal polyps. Endoscopy. 2018;50(8):790-799. doi:10.1055/a-0577-3206

14. Truscello D, Torres J, Shah M, Weston J, Blair B. 3134 rare complication of delayed bleeding after polypectomy. $A C G$. 2019;114:S1684.

15. Ket SN, Mangira D, Ng A, et al. Complications of cold versus hot snare polypectomy of 10-20 mm polyps: a retrospective cohort study. JGH Open. 2020;4(2):172-177. doi:10.1002/jgh3.12243

16. Watabe H, Yamaji Y, Okamoto $M$, et al. Risk assessment for delayed hemorrhagic complication of colonic polypectomy: polyp-related factors and patient-related factors. Gastrointest Endosc. 2006;64(1):73-78. doi:10.1016/j.gie.2006.02.054

17. Jaruvongvanich V, Prasitlumkum N, Assavapongpaiboon B, Suchartlikitwong S, Sanguankeo A, Upala S. Risk factors for delayed colonic post-polypectomy bleeding: a systematic review and meta-analysis. Int J Colorectal Dis. 2017;32(10):1399-1406. doi:10.1007/s00384-017-2870-0

18. Wu X-R, Church JM, Jarrar A, Liang J, Kalady MF. Risk factors for delayed postpolypectomy bleeding: how to minimize your patients' risk. Int $J$ Colorectal Dis. 2013;28(8):1127-1134. doi:10.1007/s00384-013-1661-5

19. Park S-K, Seo JY, Lee M-G, et al. Prospective analysis of delayed colorectal post-polypectomy bleeding. Surg Endosc. 2018;32 (7):3282-3289. doi:10.1007/s00464-018-6048-9

20. Tsuruta S, Tominaga N, Ogata S, et al. Risk factors for delayed hemorrhage after colonic endoscopic mucosal resection in patients not on antithrombotic therapy: retrospective analysis of 3844 polyps of 1660 patients. Digestion. 2019;100(2):86-92. doi:10.1159/000494455

21. Kwon MJ, Kim YS, Bae SI, et al. Risk factors for delayed post-polypectomy bleeding. Intest Res. 2015;13(2):160-165. doi:10.5217/ir.2015.13.2.160

22. Dentali F, Sironi AP, Ageno W, et al. Relationship between ABO blood group and hemorrhage: a systematic literature review and meta-analysis. Semin Thromb Hemost. 2013;39(1):72-82. doi: $10.1055 / \mathrm{s}-0032-1329550$

23. Furuhashi H, Dobashi A, Tamai N, et al. Blood group O is a risk factor for delayed post-polypectomy bleeding. Surg Endosc. 2020. doi:10.1007/s00464-020-08195-y

24. Huang RJ, Perumpail RB, Thosani N, Cheung R, Friedland S. Colonoscopy with polypectomy is associated with a low rate of complications in patients with cirrhosis. Endosc Int Open. 2016;4 (9):E947-E952. doi:10.1055/s-0042-111317

25. Lee HS, Park JJ, Kim SU, et al. Incidence and risk factors of delayed postpolypectomy bleeding in patients with chronic liver disease. Scand J Gastroenterol. 2016;51(5):618-624. doi:10.3109/00365521.2015.1121513

26. Soh H, Chun J, Hong SW, et al. Child-Pugh B or C cirrhosis increases the risk for bleeding following colonoscopic polypectomy. Gut Liver. 2020;14(6):755-764. doi:10.5009/ gnl19131 
27. Connell NT, Flood VH, Brignardello-Petersen R, et al. ASH ISTH NHF WFH 2021 guidelines on the management of von Willebrand disease. Blood Adv. 2021;5(1):301-325. doi:10.1182/ bloodadvances. 2020003264

28. Shiffman ML, Farrel MT, Yee YS. Risk of bleeding after endoscopic biopsy or polypectomy in patients taking aspirin or other NSAIDS. Gastrointest Endosc. 1994;40(4):458-462. doi:10.1016/ S0016-5107(94)70210-1

29. Sawhney MS, Salfiti N, Nelson DB, Lederle FA, Bond JH. Risk factors for severe delayed postpolypectomy bleeding. Endoscopy. 2008;40(2):115-119. doi:10.1055/s-2007-966959

30. Manocha D, Singh M, Mehta N, Murthy UK. Bleeding risk after invasive procedures in aspirin/NSAID users: polypectomy study in veterans. Am J Med. 2012;125(12):1222-1227. doi:10.1016/j. amjmed.2012.05.030

31. Biondi-Zoccai GGL, Lotrionte M, Agostoni P, et al. A systematic review and meta-analysis on the hazards of discontinuing or not adhering to aspirin among 50,279 patients at risk for coronary artery disease. Eur Heart J. 2006;27(22):2667-2674. doi:10.1093/eurheartj/ehl334

32. Veitch AM, Radaelli F, Alikhan R, et al. Endoscopy in patients on antiplatelet or anticoagulant therapy: British Society of Gastroenterology (BSG) and European Society of Gastrointestinal Endoscopy (ESGE) guideline update. Gut. 2021;70(9):1611-1628. doi:10.1136/gutjnl-2021-325184

33. Acosta RD, Abraham NS, Chandrasekhara V, et al. The management of antithrombotic agents for patients undergoing GI endoscopy. Gastrointest Endosc. 2016;83(1):3-16. doi:10.1016/j. gie.2015.09.035

34. Gandhi S, Narula N, Mosleh W, Marshall JK, Farkouh M. Metaanalysis: colonoscopic post-polypectomy bleeding in patients on continued clopidogrel therapy. Aliment Pharmacol Ther. 2013;37 (10):947-952. doi:10.1111/apt.12292

35. Chan FKL, Kyaw MH, Hsiang JC, et al. Risk of postpolypectomy bleeding with uninterrupted clopidogrel therapy in an industry-independent, double-blind, randomized trial. Gastroenterology. 2019;156(4):918-925.e1. doi:10.1053/j. gastro.2018.10.036

36. Witt DM, Delate T, McCool KH, et al. Incidence and predictors of bleeding or thrombosis after polypectomy in patients receiving and not receiving anticoagulation therapy. $J$ Thromb Haemost. 2009;7(12):1982-1989. doi:10.1111/j.1538-7836.2009.03598.x

37. Yanagisawa N, Nagata N, Watanabe K, et al. Post-polypectomy bleeding and thromboembolism risks associated with warfarin vs direct oral anticoagulants. World J Gastroenterol. 2018;24 (14):1540-1549. doi:10.3748/wjg.v24.i14.1540

38. Kim G-U, Lee S, Choe J, et al. Risk of postpolypectomy bleeding in patients taking direct oral anticoagulants or clopidogrel. Sci Rep. 2021;11(1):1-7. doi:10.1038/s41598-020-79139-8

39. Lau LH, Guo CL, Yip TC, et al. Risks of post-colonoscopic polypectomy bleeding and thromboembolism with warfarin and direct oral anticoagulants: a population-based analysis. Gut. 2021; gutjnl - 2020-323600. doi:10.1136/gutjnl-2020-323600

40. Rebello D, Bakhit M, McCarty TR, Machan JT, Nagar A, Moss SF. Heparin bridge is associated with more post-polypectomy bleeding and emergency department visits among anticoagulated patients. Ann Gastroenterol Hepatol. 2020;33(1):73-79.

41. Ishigami $\mathrm{H}$, Arai M, Matsumura $\mathrm{T}$, et al. Heparin-bridging therapy is associated with a high risk of post-polypectomy bleeding regardless of polyp size. Dig Endosc. 2017;29(1):65-72. doi: $10.1111 /$ den. 12692

42. Buddingh TK, Herngreen T, Haringsma J, et al. Location in the right hemi-colon is an independent risk factor for delayed postpolypectomy hemorrhage: a multi-center case-control study. ACG. 2011;106(6):1119.
43. Heldwein W, Dollhopf M, Rösch T, et al. The Munich Polypectomy Study (MUPS): prospective analysis of complications and risk factors in 4000 colonic snare polypectomies. Endoscopy. 2005;37(11):1116-1122. doi:10.1055/s-2005-870512

44. Kim HH, Kim JH, Park SJ, Park MI, Moon W. Risk factors for incomplete resection and complications in endoscopic mucosal resection for lateral spreading tumors. Dig Endosc. 2012;24 (4):259-266. doi:10.1111/j.1443-1661.2011.01232.x

45. Rutter MD, Nickerson C, Rees CJ, Patnick J, Blanks RG. Risk factors for adverse events related to polypectomy in the English Bowel Cancer Screening Programme. Endoscopy. 2014;46 (2):90-97. doi:10.1055/s-0033-1344987

46. Kim JH, Lee HJ, Ahn JW, et al. Risk factors for delayed post-polypectomy hemorrhage: a case-control study. J Gastroenterol Hepatol. 2013;28(4):645-649. doi:10.1111/jgh.12132

47. Zhang Q, An Li S, Chen Yu Z, et al. Assessment of risk factors for delayed colonic post-polypectomy hemorrhage: a study of 15553 polypectomies from 2005 to 2013. PLoS One. 2014;9 (10):e108290. doi:10.1371/journal.pone.0108290

48. Shinozaki S, Kobayashi Y, Hayashi Y, Sakamoto H, Lefor AK, Yamamoto H. Efficacy and safety of cold versus hot snare polypectomy for resecting small colorectal polyps: systematic review and meta-analysis. Dig Endosc. 2018;30(5):592-599. doi:10.1111/den.13173

49. Metz AJ, Bourke MJ, Moss A, Williams SJ, Swan MP, Byth K. Factors that predict bleeding following endoscopic mucosal resection of large colonic lesions. Endoscopy. 2011;43(6):506-511. doi: $10.1055 / \mathrm{s}-0030-1256346$

50. Saito Y, Fukuzawa M, Matsuda T, et al. Clinical outcome of endoscopic submucosal dissection versus endoscopic mucosal resection of large colorectal tumors as determined by curative resection. Surg Endosc. 2010;24(2):343-352. doi:10.1007/ s00464-009-0562-8

51. Fujiya M, Tanaka K, Dokoshi $T$, et al. Efficacy and adverse events of EMR and endoscopic submucosal dissection for the treatment of colon neoplasms: a meta-analysis of studies comparing EMR and endoscopic submucosal dissection. Gastrointest Endosc. 2015;81(3):583-595. doi:10.1016/j.gie.2014.07.034

52. Hassan C, Repici A, Sharma P, et al. Efficacy and safety of endoscopic resection of large colorectal polyps: a systematic review and meta-analysis. Gut. 2016;65(5):806-820. doi:10.1136/gutjnl-2014-308481

53. Siau K, Ishaq S, Cadoni S, Kuwai T, Yusuf A, Suzuki N. Feasibility and outcomes of underwater endoscopic mucosal resection for $\geq 10 \mathrm{~mm}$ colorectal polyps. Surg Endosc. 2018;32 (6):2656-2663. doi:10.1007/s00464-017-5960-8

54. Cadoni S, Ishaq S, Hassan C, et al. Water-assisted colonoscopy: an international modified Delphi review on definitions and practice recommendations. Gastrointest Endosc. 2021;93(6):14111420.e18. doi:10.1016/j.gie.2020.10.011

55. Nagl S, Ebigbo A, Goelder SK, et al. Underwater vs conventional endoscopic mucosal resection of large sessile or flat colorectal polyps: a prospective randomized controlled trial. Gastroenterology. 2021;161:1460-1474.e1. doi:10.1053/j. gastro.2021.07.044

56. Binmoeller KF, Weilert F, Shah J, Bhat Y, Kane S. "Underwater" EMR without submucosal injection for large sessile colorectal polyps (with video). Gastrointest Endosc. 2012;75 (5):1086-1091. doi:10.1016/j.gie.2011.12.022

57. Hsieh Y-H, Binmoeller K, Leung FW. Su1664 underwater polypectomy: heat-sink effect in an experimental model. Gastrointest Endosc. 2016;83(5):AB385. doi:10.1016/j.gie.2016.03.978

58. Choi AY, Moosvi Z, Shah S, et al. Underwater versus conventional EMR for colorectal polyps: systematic review and meta-analysis. Gastrointest Endosc. 2021;93(2):378-389. doi:10.1016/j.gie.2020.10.009 
59. Zhang Z, Xia Y, Cui $\mathrm{H}$, et al. Underwater versus conventional endoscopic mucosal resection for small size non-pedunculated colorectal polyps: a randomized controlled trial: (UEMR vs. CEMR for small size non-pedunculated colorectal polyps). BMC Gastroenterol. 2020;20(1):311. doi:10.1186/s12876-020-01457-y

60. Pohl H, Grimm IS, Moyer MT, et al. Effects of blended (yellow) vs forced coagulation (blue) currents on adverse events, complete resection, or polyp recurrence after polypectomy in a large randomized trial. Gastroenterology. 2020;159(1):119-128.e2. doi:10.1053/j.gastro.2020.03.014

61. Choung BS, Kim SH, Ahn DS, et al. Incidence and risk factors of delayed postpolypectomy bleeding: a retrospective cohort study. J Clin Gastroenterol. 2014;48(9):784-789. doi:10.1097/ MCG.0000000

000000027

62. Forbes N, Boyne DJ, Mazurek MS, et al. Association between endoscopist annual procedure volume and colonoscopy quality: systematic review and meta-analysis. Clin Gastroenterol Hepatol. 2020;18(10):2192-2208.e12. doi:10.1016/j.cgh.2020.03.046

63. Siau K, Crossley J, Dunckley P, et al. Direct observation of procedural skills (DOPS) assessment in diagnostic gastroscopy: nationwide evidence of validity and competency development during training. Surg Endosc. 2020;34(1):105-114. doi:10.1007/ s00464-019-06737-7

64. Chan FKL, Goh K-L, Reddy N, et al. Management of patients on antithrombotic agents undergoing emergency and elective endoscopy: joint Asian Pacific Association of Gastroenterology (APAGE) and Asian Pacific Society for Digestive Endoscopy (APSDE) practice guidelines. Gut. 2018;67(3):405-417. doi:10.1136/gutjnl-2017-315131

65. Gupta S, Miskovic D, Bhandari P, et al. A novel method for determining the difficulty of colonoscopic polypectomy. Frontline Gastroenterol. 2013;4(4):244-248. doi:10.1136/flgastro-2013-100331

66. Sehgal V, Yearwood A, Chaudhry M, et al. OTH-01 A complex lower gastrointestinal polyp MDT improves evidence-based decision making and efficiency of endoscopy scheduling. In: Gastroenterology Service. BMJ Publishing Group Ltd and British Society of Gastroenterology; 2019. doi:10.1136/gutjnl2019-bsgabstracts. 420

67. Douketis JD, Spyropoulos AC, Duncan J, et al. Perioperative management of patients with atrial fibrillation receiving a direct oral anticoagulant. JAMA Intern Med. 2019;179(11):1469-1478. doi:10.1001/jamainternmed.2019.2431

68. Haynes AB, Weiser TG, Berry WR, et al. A surgical safety checklist to reduce morbidity and mortality in a global population. $N$ Engl J Med. 2009;360(5):491-499. doi:10.1056/ NEJMsa0810119

69. Matharoo M, Thomas-Gibson S, Haycock A, Sevdalis N. Implementation of an endoscopy safety checklist. Frontline Gastroenterol. 2014;5(4):260-265. doi:10.1136/flgastro-2013100393

70. Bitar V, Martel M, Restellini S, Barkun A, Kherad O. Checklist feasibility and impact in gastrointestinal endoscopy: a systematic review and narrative synthesis. Endosc Int Open. 2021;9(3): E453-E460. doi:10.1055/a-1336-3464

71. Chang L-C, Chang C-Y, Chen C-Y, et al. 743 Cold or hot snare polypectomy for small colorectal neoplasms to prevent delayed bleeding: a multicenter randomized controlled trial (tacos trail) Gastroenterology. 2021;160(6):S- 152. doi:10.1016/S0016-5085(21) 01116-1

72. Kawamura T, Takeuchi Y, Asai S, et al. A comparison of the resection rate for cold and hot snare polypectomy for 4-9 $\mathrm{mm}$ colorectal polyps: a multicentre randomised controlled trial (CRESCENT study). Gut. 2018;67(11):1950-1957. doi:10.1136/ gutjnl-2017-314215
73. Horiuchi A, Nakayama Y, Kajiyama M, Tanaka N, Sano K, Graham DY. Removal of small colorectal polyps in anticoagulated patients: a prospective randomized comparison of cold snare and conventional polypectomy. Gastrointest Endosc. 2014;79 (3):417-423. doi:10.1016/j.gie.2013.08.040

74. Mehta D, Loutfy AH, Kushnir VM, Faulx AL, Smith ZL. Cold versus hot endoscopic mucosal resection for large sessile colon polyps: a cost-effectiveness analysis. Endoscopy. 2021. doi:10.1055/a-1469-2644

75. Tate DJ, Awadie H, Bahin FF, et al. Wide-field piecemeal cold snare polypectomy of large sessile serrated polyps without a submucosal injection is safe. Endoscopy. 2018;50(3):248-252. doi:10.1055/s-0043-121219

76. Mangira D, Cameron K, Simons K, et al. Cold snare piecemeal EMR of large sessile colonic polyps $\geq 20 \mathrm{~mm}$ (with video). Gastrointest Endosc. 2020;91(6):1343-1352. doi:10.1016/j. gie.2019.12.051

77. Di Giorgio P, De Luca L, Calcagno G, Rivellini G, Mandato M, De Luca B. Detachable snare versus epinephrine injection in the prevention of postpolypectomy bleeding: a randomized and controlled study. Endoscopy. 2004;36(10):860-863. doi:10.1055/ s-2004-825801

78. Dobrowolski S, Dobosz M, Babicki A, Dymecki D, Hać S. Prophylactic submucosal saline-adrenaline injection in colonoscopic polypectomy: prospective randomized study. Surg Endosc. 2004;18(6):990-993. doi:10.1007/s00464-003-9214-6

79. Tullavardhana $\mathrm{T}$, Akranurakkul $\mathrm{P}$, Ungkitphaiboon $\mathrm{W}$, Songtish D. Efficacy of submucosal epinephrine injection for the prevention of postpolypectomy bleeding: a meta-analysis of randomized controlled studies. Ann Med Surg (Lond). 2017;19:65-73. doi:10.1016/j.amsu.2017.05.035

80. Paspatis GA, Paraskeva K, Theodoropoulou A, et al. A prospective, randomized comparison of Adrenaline injection in combination with detachable snare versus adrenaline injection alone in the prevention of postpolypectomy bleeding in large colonic polyps. Am J Gastroenterol. 2006;101(12):2805; quiz 2913. doi:10.1111/j.1572-0241.2006.00855.X

81. Kouklakis G, Mpoumponaris A, Gatopoulou A, Efraimidou E, Manolas K, Lirantzopoulos N. Endoscopic resection of large pedunculated colonic polyps and risk of postpolypectomy bleeding with Adrenaline injection versus endoloop and hemoclip: a prospective, randomized study. Surg Endosc. 2009;23 (12):2732-2737. doi:10.1007/s00464-009-0478-3

82. Forbes N, Frehlich L, James MT, et al. Routine prophylactic endoscopic clipping is not efficacious in the prevention of delayed post-polypectomy bleeding: a systematic review and meta-analysis of randomized controlled trials. J Can Assoc Gastroenterol. 2019;2(3):105-117. doi:10.1093/jcag/gwy033

83. Yang T-C, Wu Y-H, Lee P-C, et al. Prophylactic clipping after endoscopic mucosal resection of large nonpedunculated colorectal lesions: a meta-analysis. J Gastroenterol Hepatol. 2021;36 (7):1778-1787. doi:10.1111/jgh.15472

84. Mack A, Mangira D, Moss A. Prevention of delayed post-polypectomy bleeding: should we amend the 2017 ESGE guideline? Endosc Int Open. 2020;8(9):E1111-E1114. doi:10.1055/a-1196-1602

85. Spadaccini M, Albéniz E, Pohl H, et al. Prophylactic clipping after colorectal endoscopic resection prevents bleeding of large, proximal polyps: meta-analysis of randomized trials. Gastroenterology. 2020;159(1):148-158.e11. doi:10.1053/j. gastro.2020.03.051

86. Parikh ND, Zanocco K, Keswani RN, Gawron AJ. A cost-efficacy decision analysis of prophylactic clip placement after endoscopic removal of large polyps. Clin Gastroenterol Hepatol. 2013;11 (10):1319-1324. doi:10.1016/j.cgh.2012.12.044 
87. Albéniz E, Álvarez MA, Espinós JC, et al. Clip closure after resection of large colorectal lesions with substantial risk of bleeding. Gastroenterology. 2019;157(5):1213-1221.e4. doi:10.1053/j.gastro.2019.07.037

88. Pohl H, Grimm IS, Moyer MT, et al. Clip closure prevents bleeding after endoscopic resection of large colon polyps in a randomized trial. Gastroenterology. 2019;157(4):977-984.e3. doi:10.1053/j.gastro.2019.03.019

89. Burgess NG, Bassan MS, McLeod D, Williams SJ, Byth K, Bourke MJ. Deep mural injury and perforation after colonic endoscopic mucosal resection: a new classification and analysis of risk factors. Gut. 2017;66(10):1779-1789. doi:10.1136/gutjnl-2015309848

90. Okugawa T, Oshima T, Nakai K, et al. Effect of instruction on preventing delayed bleeding after colorectal polypectomy and endoscopic mucosal resection. J Clin Med Res. 2021;10(5). doi: $10.3390 / \mathrm{jcm} 10050928$

91. Lee HS, Jeon SW, Kwon YH, et al. Prophylactic endoscopic coagulation to prevent delayed post-EMR bleeding in the colorectum: a prospective randomized controlled trial (with videos). Gastrointest Endosc. 2019;90(5):813-822. doi:10.1016/j. gie.2019.05.039

92. Subramaniam S, Kandiah K, Chedgy F, et al. A novel self-assembling peptide for hemostasis during endoscopic submucosal dissection: a randomized controlled trial. Endoscopy. 2021;53(1):27-35. doi:10.1055/a-1198-0558

93. Bahin FF, Rasouli KN, Byth K, et al. Prediction of clinically significant bleeding following wide-field endoscopic resection of large sessile and laterally spreading colorectal lesions: a clinical risk score. Am $J$ Gastroenterol. 2016;111(8):1115-1122. doi:10.1038/ajg.2016.235
94. Albéniz E, Fraile M, Ibáñez B, et al. A scoring system to determine risk of delayed bleeding after endoscopic mucosal resection of large colorectal lesions. Clin Gastroenterol Hepatol. 2016;14 (8):1140-1147. doi:10.1016/j.cgh.2016.03.021

95. Albéniz E, Gimeno-García AZ, Fraile M, et al. Clinical validation of risk scoring systems to predict risk of delayed bleeding after EMR of large colorectal lesions. Gastrointest Endosc. 2020;91 (4):868-878.e3. doi:10.1016/j.gie.2019.10.013

96. Sidhu M, Tate DJ, Desomer L, et al. The size, morphology, site, and access score predicts critical outcomes of endoscopic mucosal resection in the colon. Endoscopy. 2018;50(7):684-692. doi:10.1055/s-0043-124081

97. Rodríguez de Santiago E, Hernández-Tejero M, Rivero-Sánchez $\mathrm{L}$, et al. Management and outcomes of bleeding within 30 days of colonic polypectomy in a large, real-life, multicenter cohort study. Clin Gastroenterol Hepatol. 2021;19(4):732-742.e6. doi:10.1016/ j.cgh.2020.03.068

98. Burgess NG, Williams SJ, Hourigan LF, et al. A management algorithm based on delayed bleeding after wide-field endoscopic mucosal resection of large colonic lesions. Clin Gastroenterol Hepatol. 2014;12(9):1525-1533. doi:10.1016/j.cgh.2014.01.026

99. Liu C, Wu R, Sun X, Tao C, Liu Z. Risk factors for delayed hemorrhage after colonoscopic postpolypectomy: polyp size and operative modality. JGH Open. 2019;3(1):61-64. doi:10.1002/ jgh3.12106

100. Harada H, Miyaoka Y, Yuki T, et al. Postpolypectomy bleeding of colorectal polyps in patients with continuous warfarin and shortterm interruption of direct oral anticoagulants. Gastrointest Endosc. 2021;93(3):691-698. doi:10.1016/j.gie.2020.09.046

\section{Publish your work in this journal}

Clinical and Experimental Gastroenterology is an international, peerreviewed, open access, online journal publishing original research, reports, editorials, reviews and commentaries on all aspects of gastroenterology in the clinic and laboratory. This journal is indexed on American Chemical Society's Chemical Abstracts Service (CAS).
The manuscript management system is completely online and includes a very quick and fair peer-review system, which is all easy to use. Visit http://www.dovepress.com/testimonials.php to read real quotes from published authors. 